\title{
Efeito da Escolha da Opção "Nenhuma das Alternativas" sobre a Ressurgência de Classes de Equivalência
}

\author{
Verônica Bender Haydu ${ }^{1}$ \\ Departamento de Psicologia Geral e Análise do Comportamento da Universidade Estadual \\ de Londrina, Londrina, Brasil \\ Tatiane Carvalho Castro \\ Departamento de Psicologia da Universidade Federal de São Carlos, São Carlos, Brasil
}

\begin{abstract}
Resumo
A ressurgência de classes de equivalência tem sido demonstrada sob contingência de punição, mas raramente sob extinção. Uma explicação seriam as condições extremamente controladas dos arranjos experimentais, em que o participante é obrigado a escolher um dos estímulos de comparação. O objetivo deste estudo foi investigar o efeito de uma opção de resposta correspondente a não escolher um dos estímulos de comparação ("nenhuma das alternativas"), sobre a emergência de relações de equivalência e o efeito dessa opção sobre a ressurgência de classes de equivalência sob extinção ou punição. Dois grupos de seis participantes cada foram submetidos a um procedimento de escolha de acordo com modelo (MTS). Na Etapa 1 (Treino Inicial), relações condicionais para formar quatro classes com quatro estímulos foram reforçadas. Na Etapa 2 (Treino Tardio), as contingências foram alteradas e os 16 estímulos foram recombinados para formar quatro classes de equivalência novas. Na Etapa 3 (Ressurgência), os participantes foram expostos ao MTS sob extinção (Grupo 1) ou punição (Grupo 2) das repostas de acordo com o Treino Tardio. Durante os testes de equivalência e na condição de Ressurgência, a opção "nenhuma das alternativas" estava presente. Os dois grupos demonstraram emergência das classes de equivalência na Etapa 1. Na Etapa 3, cinco dos seis participantes do Grupo 1 não demonstraram ressurgência, mas no caso dos participantes do Grupo 2 esse fenômeno foi observado. A opção "nenhuma das alternativas" foi raramente escolhida. Conclui-se que a presença dessa opção não afetou a formação ou a ressurgência de classes de equivalência.
\end{abstract}

Palavras-chave: Ressurgência, extinção, punição, relações de equivalência, reorganização de classes de equivalência.

\section{Effect of Choosing the "None of the Alternatives" Option on Equivalence Classes Resurgence}

\begin{abstract}
The resurgence of equivalence classes has been demonstrated under a punishment contingency, but rarely under extinction. One explanation would be the extremely controlled experimental settings in which the participant is required to choose one of the comparison stimuli presented. The goals of this study were to investigate the effects of a response option corresponding to choosing none of the comparison stimuli ('no alternative') on the emergence of equivalence relations, and the effects of this option on the resurgence of equivalence classes under punishment or extinction. Two groups of six participants each
\end{abstract}

Endereço para correspondência: Centro de Ciências Biológicas, Departamento de Psicologia Geral e Análise do Comportamento, Universidade Estadual de Londrina, Av. Celso Garcia Cid, Km 380, Campus Universitário, Londrina, PR, Brasil 86051-970. Caixa-postal: 6001. E-mail: haydu@uel.br 
were exposed to three phases of a matching-to-sample (MTS) procedure. In Phase 1 (Early-training), conditional relations were trained to establish four equivalence classes with four visual stimuli. In Phase 2 (Late-training), the contingencies were changed and these 16 stimuli were recombined to form four new equivalence classes. In Phase 3 (Resurgence), participants were exposed to MTS trials under extinction (Group 1) or punishment (Group 2) of the Late-training-consistent responses. During equivalence relations tests and the resurgence condition the "no alternative" option was presented. Both groups showed emergence of the equivalence classes in Phase1. In Phase 3, five of six participants in Group 1 showed no resurgence of Early-training-consistent responses, but in the case of participants in Group 2 this phenomenon was observed. The "no alternative" response was rarely emitted. It was concluded that the presence of this option did not affect the formation or the resurgence of equivalence classes.

Keywords: Resurgence, extinction, punishment, equivalence relations, reorganization of equivalence classes.

\section{Efecto de Elegir la Opción "Ninguna de las Alternativas" en el Resurgimiento de las Clases de Equivalencia}

\section{Resumen}

El resurgimiento de las clases de equivalencia se ha demostrado en la contingencia de castigo, pero rara vez en la extinción. Una explicación podría ser las condiciones muy controladas de las disposiciones experimentales, en el que el participante está obligado a elegir uno de los estímulos de comparación. El objetivo de este estudio fue investigar el efecto de una opción de respuesta correspondiente de no elegir uno de los estímulos de comparación ("ninguna de las alternativas"), en el surgimiento de relaciones de equivalencia y el efecto de esta opción en el resurgimiento de las clases de equivalencia con la extinción o el castigo. Dos grupos de seis participantes cada uno se sometió a un procedimiento de igualación de la muestra (MTS). En el Paso 1 (Entrenamiento Inicial), las relaciones condicionales para formar cuatro clases con cuatro estímulos fueron reforzadas. En el Paso 2 (Entrenamiento Tardío), las contingencias se han cambiado y los 16 estímulos fueron recombinados para formar cuatro nuevas clases de equivalencia. En el Paso 3 (Resurgimiento), los participantes fueron expuestos a ensayos de MTS en extinción (Grupo 1) o castigo (Grupo 2) de las respuestas consistentes con el Entrenamiento Tardío. Durante las pruebas de equivalencia y la condición de resurgimiento, la opción "ninguna de las alternativas" estuvo presente. Ambos grupos demostraron el resurgimiento de las clases de equivalencia en el Paso 1. En el Paso 3, cinco de los seis participantes en el Grupo 1 no mostró resurgimiento, pero en el caso de los participantes del Grupo 2 este fenómeno se observó. La opción "ninguna de las alternativas" fue elegido en raras ocasiones. Se concluyó que la presencia de esta opción no afectó a la formación o el resurgimiento de las clases de equivalencia.

Palabras clave: Resurgimiento, extinción, castigo, relaciones de equivalencia, reorganización de las clases de equivalencia.

Equivalência de estímulos foi caracterizada como sendo um modelo descritivo que possibilita a investigação de comportamentos complexos com o rigor do controle experimental. Assim, podem ser encontrados na bibliografia da Análise do Comportamento estudos nos quais a formação, a manutenção e a reemergência de classes de equivalência foram conduzidos com o objetivo de investigar fenômenos clássicos da
Psicologia como a linguagem, a cognição, a memória e o comportamento simbólico (e.g., Bortoloti, de Rose, \& Galvão, 2005; Magalhães \& Assis, 2011; Sidman \& Cresson, 1973; Souza, Goyos, Silvares, \& Saunders, 2007; para revisão ver, de Rose, Kato, Thé, \& Kledaras, 1997; Green \& Saunders, 1998; Sidman, 1994). Outro fenômeno comportamental que, também, passou a ser investigado com o modelo da equivalência 
de estímulos é a ressurgência de comportamentos induzida por punição e por extinção (e.g., Wilson \& Hayes, 1996).

O procedimento básico para que se possa observar a ressurgência de comportamentos consiste em reforçar uma resposta (identificada como R1), em seguida, reforçar outra resposta sob condições semelhantes (identificada como R2) e, finalmente, submeter R2 a uma contingência que diminui a probabilidade de R2, como a extinção e a punição, enquanto R1 também não deve ser reforçada. A ocorrência de R1 com uma frequência maior do que a de R2 é interpretada como uma demonstração de ressurgência de R1 (Epstein, 1983). No caso da ressurgência de classes de equivalência, o conjunto de classes de estímulos inicialmente formado é considerado como sendo a R1. Após ter sido demonstrada a emergência de R1, as contingências que estabelecem as relações condicionais entre os estímulos são alteradas para formar novas classes. Esse novo conjunto de classes de equivalência (classes reorganizadas) corresponde à R2. Assim, esse procedimento viabiliza o condicionamento de $\mathrm{R} 1$ e de R2, e as condições para a ressurgência de R1 durante a extinção ou a de R2 (para revisão ver, Doughty \& Oken, 2008; Lattal, \& St. Peter Pipkin, 2009; Villas-Bôas, Murayama, \& Tomanari, 2005).

Quatro estudos empíricos sobre ressurgência de classes de equivalência da bibliografia serão aqui considerados: Castro e Haydu (2009); Haydu, Batista e Serpeloni (2007); Hernández, Medina e Erazo (2008); Wilson e Hayes (1996). O primeiro estudo foi o de Wilson e Hayes (1996), do qual participaram 25 estudantes universitários, submetidos ao procedimento de escolha de acordo com o modelo (MTS) em computador. O treino visou reforçar relações condicionais entre estímulos (estabelecimento de linha de base) para formar três classes com quatro estímulos cada uma - condição de ensino de R1 ou Treino Inicial (TI). Durante esse treino, as respostas que estavam de acordo com as contingências estabelecidas pelos experimentadores (acertos) eram seguidas por feedback positivo ("CORRECT" e "EXCELLENT") e as que não estavam de acordo com essas contingências (erros) eram seguidas de feedback negativo
("WRONG'). Testes subsequentes das relações emergentes de simetria e de equivalência foram realizados em extinção. Ao demonstrar a formação das classes de equivalência nesse teste (critério de $90 \%$ de acertos), os participantes eram submetidos a contingências, em que as relações entre os estímulos eram alteradas para formar outras três classes de equivalência, ou seja, a formação de novas relações de linha de base (LB). Isso caracterizou o ensino de R2 ou Treino Tardio (TT). Nas fases subsequentes foram realizados: o teste das relações emergentes de simetria e de equivalência originadas do TT; o teste das relações de LB do TT, um novo teste de simetria e de equivalência, em que as respostas de escolha que estavam de acordo com o TT produziam consequências punitivas (o feedback negativo); e um novo teste das relações de LB, para verificar se após a punição das relações emergentes, haveria uma alteração nas respostas de escolha dos estímulos das relações de LB.

Os dados obtidos por Wilson e Hayes (1996) permitem verificar que, sob a condição de extinção, os participantes tenderam a responder de acordo com o TT nos testes de simetria e de equivalência, demonstrando a reorganização das classes de equivalência. No teste de LB, a maior parte dos participantes respondeu de acordo com as relações de LB modificadas, isto é, de acordo com o TT. Na condição de punição, a maioria dos participantes passou a responder de acordo com o TI, demonstrando a ressurgência das classes de equivalência. Na última fase, verificou-se que a punição afetou também as relações de LB, uma vez que a maioria dos participantes respondeu de acordo como o TI. Os autores concluíram que as classes foram reorganizadas e que a ressurgência foi demonstrada em condições que envolveram respostas relacionais derivadas. Segundo Wilson e Hayes, esses resultados permitem afirmar que o responder relacional derivado apresenta variabilidade, podendo ser modificado com a alteração nas contingências, mas que essa variabilidade é restringida pela história de reforço dos participantes. Além disso, eles destacaram que o efeito de ressurgência foi obtido em uma condição na qual os participantes tinham apenas três escolhas, sendo uma dessas escolhas punida, o que permite questionar se esse efeito 
seria reproduzido se a condição fosse de operante livre. Assim, sugeriram que examinar o efeito de ressurgência de classes de equivalência em condições menos restritas seria importante para que a conclusão por eles apresentada possa vir a ser generalizada.

Um estudo subsequente desenvolvido por Hernández et al. (2008) com estudantes do Ensino Médio, envolveu fases de procedimento correspondentes às fases do estudo de Wilson e Hayes (1996). Os dados obtidos Hernández et al. apresentam grande variabilidade no teste das relações emergentes do TT: apenas três dos sete participantes apresentaram reorganização das classes de acordo com TT e dois desse três apresentaram ressurgência das classes de equivalências $(43 \%$ e $100 \%$ de respostas de acordo com $\mathrm{TI})$.

Outro estudo que replicou o de Wilson e Hayes (1996) foi desenvolvido por Haydu et al. (2007, Experimento 2), tendo sido investigado o efeito do procedimento de extinção sobre a probabilidade de ressurgência de classes de equivalência emergentes de relações condicionais instruídas e de classes de equivalência emergentes de relações condicionais modeladas por contingências. Os participantes foram distribuídos em dois grupos. Para o Grupo 1, as relações condicionais entre os estímulos foram instruídas com o uso de protocolos impressos (ver Eikeseth, Rosales-Ruiz, Duarte, \& Baer, 1997). O Grupo 2 foi submetido ao procedimento no computador, sendo as relações condicionais entre os estímulos modeladas pelas contingências, tal como no experimento de Wilson e Hayes. As etapas do procedimento de ambos os grupos foi semelhante: (a) TI; (b) teste das relações emergentes; (c) TT; (d) teste das relações emergentes sob contingência de extinção; (e) o mesmo teste de relações emergentes foi apresentado repetidas vezes sem que nenhum feedback para as respostas e sem nenhuma informação apresentada pelo experimentador referente à repetição, caracterizando o procedimento de extinção; (f) teste de ressurgência, que consistiu de um arranjo em que todos os estímulos discriminativos referentes às relações condicionais estabelecidas no TI e no TT eram apresentados nas tentativas.
Verificou-se que os dois tipos de procedimentos (no computador e com protocolos impressos) levaram à formação e a reorganização das classes de equivalência. Nos testes de ressurgência, verificou-se que todos os participantes do Grupo 1 e sete dos oito participantes do Grupo 2 responderam predominantemente de acordo com o TT, não demonstrando a ressurgência das classes de equivalência. As autoras levantaram a hipótese de que a reapresentação dos blocos de teste sem consequências diferenciais possa não ter funcionado como extinção, não estabelecendo, portanto, a condição necessária para a ressurgência dos comportamentos.

Diante da demonstração de ressurgência com o procedimento de punição (Wilson \& Hayes, 1996) e a falha na obtenção da ressurgência com o procedimento de extinção (Haydu et al., 2007), Castro e Haydu (2009) conduziram um estudo cujo objetivo principal foi o de comparar o efeito desses dois tipos de procedimento na ressurgência de relações equivalentes com um delineamento de grupo. $\mathrm{O}$ procedimento teve três etapas: as Etapas 1 e 2 eram iguais para os dois grupos e a Etapa 3, diferente. Na Etapa 1, foi realizado o TI e foi testada e demonstrada a formação de quatro classes com quatro estímulos cada uma, o que gerava um arranjo de contingências com quatro estímulos de escolha. $\mathrm{Na}$ Etapa 2, as contingências foram modificadas para o estabelecimento de quatro novas classes de equivalência (TT). Em seguida, um dos grupos foi submetido ao procedimento de extinção e o outro ao de punição. A extinção caracterizou-se pela reapresentação sucessiva dos blocos de tentativas, sem que nenhuma consequência fosse liberada, qualquer que fosse a resposta do participante (respostas e acordo com o TI, o TT ou as que eram apresentadas diante dos outros dois estímulos de comparação, designada "outras respostas"). A punição caracterizou-se pela apresentação do feedback negativo "você errou" para as respostas consistentes com o TT e extinção das demais respostas. Os critérios para considerar que as respostas tinham sido extintas ou enfraquecidas pela punição era de no máximo $10 \%$ de respostas consistentes com o TT. No entanto, na condição de extinção, os participantes mos- 
traram sentir desconforto, fazendo comentários de que o procedimento estava muito cansativo devido às repetições, após um número de blocos superiores a 25 , o que levou as pesquisadoras a estabelecerem post hoc um critério adicional de serem realizados no máximo de 30 blocos de extinção ou de punição. Inicialmente o critério era o de que os participantes seriam submetidos a blocos sucessivos até que a porcentagem de repostas de acordo com o TT fosse inferior $10 \%$.

Os resultados de Castro e Haydu (2009) revelaram que não houve alterações na proporção de respostas do tipo TT e TI, quando o comportamento de responder às relações tardiamente treinadas foi submetido ao procedimento de extinção. O grupo que teve as respostas de acordo com TT punidas apresentou alteração do comportamento de modo que todos os participantes diminuíram a frequência das respostas consistentes com esse treino para menos de $10 \%$. Os resultados corroboram os resultados anteriores em que foi demonstrada a ressurgência de classes de equivalência com punição (Hernández et al., 2008; Wilson \& Hayes, 1996), mas não houve ressurgência com extinção (Haydu et al., 2007). Castro e Haydu, assim como Wilson e Hayes, destacaram ser importante ampliar a discussão do que possa ser considerado extinção de classes de estímulos equivalentes e sugeriram que existe a necessidade de se testar um procedimento em uma condição na qual o participante não tenha necessariamente que escolher um dos estímulos de comparação para que as tentativas sucessivas sejam apresentadas, pois nos estudos de ressurgência em condições de operante livre (e.g., Reed \& Morgan, 2006), os sujeitos podem apresentar qualquer tipo de comportamento viável na situação experimental, além de responderem aos estímulos arranjados experimentalmente. No caso dos estudos baseados no modelo da equivalência de estímulos, os participantes são instruídos de que devem escolher um dos estímulos de comparação e da condição de que devem responder para concluir o experimento, e as respostas ficam limitadas aos estímulos de comparação apresentados pelos experimentadores.

A sugestão feita por Castro e Haydu (2009) em relação à possibilidade de o participante não ter que escolher, necessariamente, um dos estímulos de comparação do arranjo de contingências é viabilizada com o procedimento de escolha de acordo com modelo que foi empregado por Duarte, Eikeseth, Rosales-Ruiz e Baer (1998). Nesse procedimento, foi incluída a oportunidade de uma resposta de não escolher um dos estímulos de comparação, a opção "can't answer". Participaram desse estudo, dois grupos de estudantes universitários, ambos submetidos a um treino em que as relações condicionais eram diretamente instruídas. As instruções e os estímulos-modelo e de comparação eram apresentados em protocolos impressos. Um dos grupos tinha a opção "can't answer" e o outro não. Verificou-se que $66 \%$ dos participantes do grupo sem a opção "can 't answer" formaram as classes de equivalência e apenas $27 \%$ do grupo que tinha disponível essa opção formaram as classes.

Apesar de a opção de poder não escolher um dos estímulos de comparação ser uma variável que possivelmente reduz a probabilidade de emergirem relações de equivalência, ela torna a situação experimental mais próxima do que acontece no cotidiano (Smeets, Dymond, \& Barnes-Holmes, 2000) e, também, torna o contexto experimental um pouco mais próximo daqueles de estudos clássicos de ressurgência (ver, Villas-Bôas et al., 2005). Assim, considerando que os participantes dos estudos de ressurgência aqui revisados (Castro \& Haydu, 2009; Haydu et al., 2007; Hernández et al., 2008; Wilson \& Hayes, 1996) não tiveram muitas alternativas de escolha na fase de ressurgência, pois podiam emitir apenas respostas de acordo com o TI, respostas de acordo com o TT ou respostas que eram as corretas diante dos estímulos-modelo das demais classes que estavam sendo treinada ("outras respostas"), formulou-se o objetivo do presente estudo, que consistiu em replicar o estudo de Castro e Haydu (2009), acrescentando uma alternativa de resposta que corresponde a não escolher um dos estímulos de comparação apresentada nos testes de relações emergentes e na fase de ressurgência. Assim, o presente estudo visou investigar: (a) o efeito da opção de poder clicar com o mouse sobre uma chave de resposta que corresponde a não escolher um dos estímulos de comparação ("nenhuma das alternativas"), sobre a emergên- 
cia de relações de equivalência; e (b) o efeito da opção de escolher "nenhumas das alternativas", sobre a ressurgência de classes de equivalência inicialmente treinadas, após extinção ou a punição das respostas treinadas tardiamente.

\section{Método}

\section{Participantes}

Os alunos de uma turma do $1^{\circ}$ ano de um curso de Medicina Veterinária de uma instituição pública foram convidados a participar da pesquisa. Os participantes que se candidataram foram informados de que a participação era voluntária e que a seleção seria feita por sorteio. Doze participantes de ambos os sexos e com idade variando de 19 a 26 anos foram sorteados, sendo distribuídos em dois grupos (Grupo Extinção e Grupo Punição). O Grupo Extinção ficou com três participantes de cada gênero e o Grupo Punição com quatro participantes do gênero feminino e dois do gênero masculino. Os participantes sorteados concordaram em participar da pesquisa assinando o Termo de Consentimento Livre e Esclarecido aprovado pelo Comitê de Ética da instituição das autoras.

\section{Materiais e Equipamento}

Dois computadores Pentium com monitor colorido e recurso multimídia e o Software Equivalência (desenvolvido por Edson dos Santos Cordeiro, em 2001) que permite ensinar relações condicionais entre estímulos por meio do procedimento de escolha de acordo com o modelo (MTS). Figuras não familiares, semelhantes às usadas por Spencer e Chase (1996), foram utilizadas como estímulos. As figuras foram especificadas arbitrariamente para quatro classes, cada uma com quatro estímulos. O programa de computador estava configurado para que um estímulo-modelo fosse apresentado sempre ao centro da tela do monitor e os quatro estímulos de comparação distribuídos equidistantemente em seus quatro cantos. A apresentação dos estímulos era aleatorizada nas quatro posições da tela e cada estímulo era apresentado o mesmo número de vezes em cada posição. Além dos quatro es- tímulos, foi programado para ser apresentado na parte inferior central da tela, entre dois estímulos de comparação um quadrado igual ao que continha os demais estímulos, no mesmo tamanho e forma que os estímulos de comparação, com a mensagem "nenhuma das alternativas" impressa. Essa chave de resposta foi considerada correspondente à opção de não escolher um dos estímulos de comparação. O programa de computador permitia configurar ou não consequências diferenciais que informavam se a resposta estava correta ou incorreta (feedback), sendo elas "Você acertou" ou "Você errou", respectivamente. A mensagem de acerto ou de erro era apresentada juntamente com uma pequena janela com a mensagem "OK". Todos os estímulos de uma tentativa e a mensagem com a consequência das respostas permaneciam na tela até que o participante clicar sobre o "OK", o que leva ao desaparecimento desses estímulos e inicia uma nova tentativa, sem intervalo entre elas. $\mathrm{O}$ participante não tinha acesso ao contador de pontos que ele fazia.

\section{Procedimento}

Os participantes dos dois grupos (Grupo Extinção e Grupo Punição) foram submetidos a procedimentos distintos, conforme será especificado a seguir. O procedimento era formado por três etapas com sessões que duravam aproximadamente de 90 min cada uma. Os participantes foram submetidos ao procedimento individualmente e o número de sessões variou de acordo com o desempenho de cada um (três a cinco). $\mathrm{Na}$ Etapa 1, foi feito o TI, que consistiu do treino das relações condicionais entre estímulos para formar quatro classes de equivalência com quatro estímulos cada uma (A1-B1-C1-D1, A2-B2C2-D2, A3-B3-C3-D3, A4-B4-C4-D4) e foram aplicados os testes das relações emergentes. $\mathrm{Na}$ Etapa 2, foi feito o TT, em que as relações condicionais para a formação de quatro classes de equivalência novas com os mesmos estímulos foram treinadas (A1-B2-C3-D4, A2-B3-C4-D1, A3-B4-C1-D2, A4-B1-C2-D3), e os testes das relações emergentes foram aplicados. $\mathrm{O}$ treino e os testes eram feitos por meio do procedimen- 
to de escolha de acordo com o modelo, com a estrutura de treino "comparação como nódulo" (CaN [Comparison as Node]), como em Castro e Haydu (2009). Na Etapa 3 (Condição de Ressurgência), foram conduzidos blocos de testes: o Grupo Punição teve as respostas que estavam de acordo com o TT punidas e as demais repostas colocadas em extinção; o Grupo Extinção não tinham consequências para qualquer tipo de resposta. O procedimento foi diferente para os dois grupos, também, quanto às consequências das respostas nos treinos: o Grupo Punição recebeu feedback tanto para as respostas corretas quanto para as incorretas ("Você acertou"; "Você errou", respectivamente) e o Grupo Extinção recebeu feedback apenas para as respostas corretas ("Você acertou"). Essa medida foi adotada para uniformizar para cada grupo a contingência estabelecida nos treinos (Etapa 1 e Etapa 2) para as respostas incorretas com a da condição de ressurgência (Etapa 3). No caso do Grupo Extinção, para verificar a ressurgência das classes de equivalência não era apresentado feedback após as respostas, por isso, no treino, a consequência das respostas incorretas era a ausência de feedback. No caso do Grupo Punição, que recebia feedba$c k$ negativo na condição de ressurgência para as respostas que estavam de acordo com o TT, a consequência das respostas incorretas durante os treinos era esse mesmo feedback negativo. Nenhum outro tipo de consequência era fornecido na condição de ressurgência. A distribuição da sequência de fases do procedimento encontra-se resumida na Tabela 1, em que estão especificadas também as fases de reexposição quando o critério de acertos não era atingido.

No início da Etapa 1, cada participante recebeu a seguinte instrução:

Aparecerá um estímulo no centro da tela do computador e quatro outros estímulos, um em cada canto. O estímulo do centro é o estímulo-modelo e os outros quatro são estímulos de comparação. Você deverá escolher um dos quatro estímulos que estão em cada canto da tela, posicionar o mouse sobre ele e clicar. Como as relações entre os estímulos não são por semelhança física, ou seja, são arbitrárias, você deverá desco- brir como os estímulos se relacionam por meio das consequências das escolhas que você fizer, que a princípio serão aleatórias. $\mathrm{Na}$ Etapa 1, foram executados, em diferentes fases, os blocos de treino das relações condicionais de LB, intercalados por blocos de testes das relações de LB e de simetria misturadas (Teste LB/Sim). Os blocos de treino eram formados por 16 tentativas, sendo quatro de cada relação. Na Fase 1, cada uma das contingências para o estabelecimento das relações de LB (B1A1, B2-A2, B3-A3, B4-A4) foi apresentada quatro vezes em ordem aleatória. Esse bloco de treino era repetido até que o participante atingisse $90 \%$ de acertos (reexposições à Fase 1.1). Após atingir o critério de acertos nesse bloco, o participante realizava o teste das relações de simetria $\mathrm{AB}$, contendo 16 tentativas de relações de LB intercaladas - Teste LB/Sim (BA e AB). Se os participantes atingissem o critério de $90 \%$ de acertos nesse teste, era submetido ao procedimento do bloco de treino das relações CA; se não atingissem o critério, o bloco de treino das relações BA era repetido (reexposição à Fase 1.1), e em seguida, ser aplicado o Teste LB/Sim (BA e $\mathrm{AB}$ ) novamente. Essa sequência era repetida quantas vezes fossem necessárias para $\mathrm{o}$ critério ser atingido.

As relações do tipo CA eram treinadas e testadas da mesma forma que as relações BA. Se o participante não atingisse o critério de acertos era feito a reexposição à Fase 1.3; se atingisse, era aplicado o Teste LB/Sim (CA e AC). Se o participante não atingisse o critério de acertos nesse teste, era feito a reexposição à Fase 1.3; se atingisse era aplicado o teste das relações de equivalência, composto por 32 tentativas das relações emergentes $\mathrm{BC}$ e $\mathrm{CB}$ (Teste de Equivalência $\mathrm{BC} / \mathrm{CB})$. Se o participante não atingisse o critério de acertos no Teste de Equivalência BC/ $\mathrm{CB}$, era feito a reexposição à Fase 1.1; se o participante atingisse o critério de acertos nesse teste, as relações DA eram treinadas e era feito o Teste $\mathrm{LB} / \mathrm{Sim}$ (DA e AD). As reexposições seguiam os mesmos critérios das fases anteriores, conforme está especificado na Tabela 1. No final da Etapa 1, era aplicado o Teste de Equivalência $\mathrm{BD} / \mathrm{DB} /$ $\mathrm{CD} / \mathrm{DC}$, com 64 tentativas, com reexposição à 


\section{Tabela 1}

Etapas, Fases, Tipo de Relação e Número de Tentativas por Bloco e Fase de Reexposição (Reexp.)

\begin{tabular}{|c|c|c|c|c|}
\hline Etapas & Fases & Relações treinadas ou testadas & $\mathrm{N}^{\mathrm{o}}$ de tent. & Reexp. \\
\hline \multirow[t]{9}{*}{1} & 1.1 Treino BA & B1A1, B2A2, B3A3, B4A4 & 16 & 1.1 \\
\hline & 1.2 Teste LB/Sim & B1A1, B2A2, B3A3, B4A4, A1B1, A2B2, A3B3, A4B4 & 32 & 1.1 \\
\hline & 1.3 Treino CA & $\mathrm{C} 1 \mathrm{~A} 1, \mathrm{C} 2 \mathrm{~A} 2, \mathrm{C} 3 \mathrm{~A} 3, \mathrm{C} 4 \mathrm{~A} 4$ & 16 & 1.3 \\
\hline & 1.4 Teste LB/Sim & $\mathrm{C} 1 \mathrm{~A} 1, \mathrm{C} 2 \mathrm{~A} 2, \mathrm{C} 3 \mathrm{~A} 3, \mathrm{C} 4 \mathrm{~A} 4, \mathrm{~A} 1 \mathrm{C} 1, \mathrm{~A} 2 \mathrm{C} 2, \mathrm{~A} 3 \mathrm{C} 3, \mathrm{~A} 4 \mathrm{C} 4$ & 32 & 1.3 \\
\hline & $\begin{array}{l}1.5 \text { Teste Equiv } \\
\mathrm{BC} / \mathrm{CB}\end{array}$ & $\mathrm{B} 1 \mathrm{C} 1, \mathrm{~B} 2 \mathrm{C} 2, \mathrm{~B} 3 \mathrm{C} 3, \mathrm{~B} 4 \mathrm{C} 4, \mathrm{C} 1 \mathrm{~B} 1, \mathrm{C} 2 \mathrm{~B} 2, \mathrm{C} 3 \mathrm{~B} 3, \mathrm{C} 4 \mathrm{~B} 4$ & 32 & 1.1 \\
\hline & 1.6 Treino DA & D1A1, D2A2, D3A3, D4A4 & 16 & 1.6 \\
\hline & 1.7 Teste LB/Sim & D1A1, D2A2, D3A3, D4A4, A1D1, A2D2, A3D3, A4D4 & 32 & 1.6 \\
\hline & $\begin{array}{l}1.8 \text { Teste Equiv } \\
\mathrm{BD} / \mathrm{DB} / \mathrm{CD} / \mathrm{DC}\end{array}$ & $\begin{array}{l}\text { B1D1, B2D2, B3D3, B4D4, D1B1, D2B2, D3B3, D4B4, } \\
\text { C1D1, C2D2, C3D3, C4D4, D1C1, D2C2, D3C3, D4C4 }\end{array}$ & 64 & 1.1 \\
\hline & 1.9 Teste Misto & $\begin{array}{l}\text { B1A1, B2A2, B3A3, B4A4, A1B1, A2B2, A3B3, A4B4, } \\
\text { C1A1, C2A2, C3A3, C4A4, A1C1, A2C2, A3C3, A4C4, } \\
\text { D1A1, D2A2, D3A3, D4A4, A1D1, A2D2, A3D3, A4D4, } \\
\text { B1C1, B2C2, B3C3, B4C4, C1B1, C2B2, C3B3, C4B4, } \\
\text { B1D1, B2D2, B3D3, B4D4, D1B1, D2B2, D3B3, D4B4, } \\
\text { C1D1, C2D2, C3D3, C4D4, D1C1, D2C2, D3C3, D4C4 }\end{array}$ & 192 & 1.1 \\
\hline \multirow[t]{9}{*}{2} & 2.1 Treino BA & $\mathrm{B} 2 \mathrm{~A} 1, \mathrm{~B} 3 \mathrm{~A} 2, \mathrm{~B} 4 \mathrm{~A} 3, \mathrm{~B} 1 \mathrm{~A} 4$ & 16 & 2.1 \\
\hline & 2.2 Teste LB/Sim & $\mathrm{B} 2 \mathrm{~A} 1, \mathrm{~B} 3 \mathrm{~A} 2, \mathrm{~B} 4 \mathrm{~A} 3, \mathrm{~B} 1 \mathrm{~A} 4, \mathrm{~A} 1 \mathrm{~B} 2, \mathrm{~A} 2 \mathrm{~B} 3, \mathrm{~A} 3 \mathrm{~B} 4, \mathrm{~A} 4 \mathrm{~B} 1$ & 32 & 2.1 \\
\hline & 2.3 Treino CA & $\mathrm{C} 3 \mathrm{~A} 1, \mathrm{C} 4 \mathrm{~A} 2, \mathrm{C} 1 \mathrm{~A} 3, \mathrm{C} 2 \mathrm{~A} 4$ & 16 & 2.3 \\
\hline & 2.4 Teste LB/Sim & C3A1, C4A2, C1A3, C2A4, A1C3, A2C4, A3C1, A4C2 & 32 & 2.3 \\
\hline & $\begin{array}{l}2.5 \text { Teste Equiv. } \\
\mathrm{BC} / \mathrm{CB}\end{array}$ & $\mathrm{B} 2 \mathrm{C} 3, \mathrm{~B} 3 \mathrm{C} 4, \mathrm{~B} 4 \mathrm{C} 1, \mathrm{~B} 1 \mathrm{C} 2, \mathrm{C} 3 \mathrm{~B} 2, \mathrm{C} 4 \mathrm{~B} 3, \mathrm{C} 1 \mathrm{~B} 4, \mathrm{C} 2 \mathrm{~B} 1$ & 32 & 2.1 \\
\hline & 2.6 Treino DA & D4A1, D1A2, D2A3, D3A4 & 16 & 2.6 \\
\hline & 2.7 Teste LB/Sim & D4A1, D1A2, D2A3, D3A4, A1D4, A2D1, A3D2, A4D3 & 32 & 2.6 \\
\hline & $\begin{array}{l}2.8 \text { Teste Equiv. } \\
\mathrm{BD} / \mathrm{DB} / \mathrm{CD} / \mathrm{DC}\end{array}$ & $\begin{array}{l}\text { B2D4, B3D1, B4D2, B1D3, D4B2, D1B3, D2B4, D3B1, } \\
\text { C3D4, C4D1, C1D2, C2D3, D4C3, D1C4, D2C1, D3C2 }\end{array}$ & 64 & 2.1 \\
\hline & 2.9 Teste Misto & $\begin{array}{l}\text { B2A1, B3A2, B4A3, B1A4, A1B2, A2B3, A3B4, A4B1, } \\
\text { C3A1, C4A2, C1A3, C2A4, A1C3, A2C4, A3C1, A4C2, } \\
\text { B2C3, B3C4, B4C1, B1C2, C3B2, C4B3, C1B4, C2B1, } \\
\text { D4A1, D1A2, D2A3, D3A4, A1D4, A2D1, A3D2, A4D3, } \\
\text { B2D4, B3D1, B4D2, B1D3, D4B2, D1B3, D2B4, D3B1, } \\
\text { C3D4, C4D1, C1D2, C2D3, D4C3, D1C4, D2C1, D3C2 }\end{array}$ & 192 & 2.1 \\
\hline 3 & $\begin{array}{l}\text { Condição de } \\
\text { Ressurgência }\end{array}$ & $\begin{array}{l}\text { B1A*, B2A, B3A, B4A, A1B, A2B, A3B, A4B, C1A, C2A, } \\
\text { C3A, C4A, A1C, A2C, A3C, A4C, D1A, D2A, D3A, D4A, } \\
\text { AA1D, A2D, A3D, A4D, B1C, B2C, B3C, B4C, C1B, } \\
\text { C2B,C3B, C4B, B1D, B2D, B3D, B4D, D1B, D2B, D3B, } \\
\text { D4B, D1C, D2C, D3C, D4C, C1D, C2D, C3D, C4D }\end{array}$ & 48 & \\
\hline
\end{tabular}

Nota. ${ }^{*}$ O segundo estímulo das relações não tem número porque nesta etapa não havia uma resposta correta, ou seja, não havia uma reposta que estivesse de acordo com uma relação estabelecida pelos experimentadores. 
Fase 1.1, se o critério não fosse atingido. Nesse bloco, além dos quatro estímulos de comparação, foi incluída a opção de resposta "nenhuma das alternativas". Cada relação era testada quatro vezes, variando a posição dos estímulos de comparação. A opção "nenhuma das alternativas" foi introduzida apenas em uma das tentativas de cada relação. Isso foi feito para prevenir que a apresentação repetida dessa opção, em presença da qual uma resposta nunca era reforçada, levasse os participantes formularem uma regra, como, por exemplo, de que essa opção não tinha função. No Teste de Equivalência $\mathrm{BD} / \mathrm{DB} / \mathrm{CD} /$ DC, se o critério fosse atingido, era aplicado o Teste Misto. Esse teste era composto de todas as relações de LB, de simetria e de equivalência aleatorizadas, apresentadas quatro vezes cada uma, totalizando 192 tentativas. A opção "nenhuma das alternativas" estava disponível, nesse bloco em apenas uma das quatro tentativas de cada relação como no teste de equivalência. Se, nessa fase, o critério de acertos não fosse atingido, o participante era submetido ao treino BA novamente (reexposição à Fase 1.1).

Na Etapa 2 (TT), as contingências foram alteradas e relações condicionais novas, envolvendo os mesmos estímulos das classes anteriormente formadas, reforçadas. Isso possibilitava estabelecer um novo conjunto de relações de LB e a emergência das classes A1-B2-C3D4, A2-B3-C4-D1, A3-B4-C1-D2 e A4-B1-C2D3. A sequência do procedimento foi igual a da Etapa 1.

Na Etapa 3 (Condição de Ressurgência), foram testadas as mesmas relações do Teste Misto, mas com apenas uma tentativa de cada relação, totalizando 48 tentativas. Estava disponível a opção "nenhuma das alternativas", mas somente naquelas tentativas em que as relações de equivalência eram testadas. Nessa etapa, os participantes do Grupo Extinção foram submetidos a um procedimento em que qualquer que fosse a resposta dada, nenhuma consequência era apresentada e os participantes do Grupo Punição recebiam feedback negativo ("Você errou") para respostas consistentes com o TT. As respostas consistentes com o TI, as respostas "nenhuma das alternativas" e as respostas que não estivessem de acordo com nenhum dos dois treinos (escolhas de estímulos que correspondem às outras classes, identificadas pelo rótulo "Outras Respostas"), não tiveram qualquer tipo de consequência diferencial. A participação no experimento era encerrada quando os participantes apresentavam no máximo $10 \%$ de respostas consistentes com o TT ou 30 blocos de acordo com o que foi estabelecido por Castro e Haydu (2009). Na Tabela 1, o segundo estímulo das relações especificadas não tem número porque nessa etapa não havia uma resposta considerada correta. As respostas dos participantes foram classificadas de acordo como as seguintes categorias: TI, TT, "nenhuma das alternativas". Aquelas que não fossem de nenhum desses tipos foi classificada como "Outras Respostas".

\section{Resultados}

A Tabela 2 apresenta o número de repetições dos blocos de treino e teste necessárias para atingir o critério de acertos dos participantes do Grupo Extinção, nas Etapas 1 e 2 do procedimento. Nessa tabela, o sinal de adição $(+)$ indica que o participante não atingiu o critério de $90 \%$ de acertos em um teste, sendo submetido novamente às fases anteriores, e os algarismos, o número de vezes que executou os blocos. $\mathrm{O}$ algarismo $1^{*}$ (com asterisco) assinala os testes de equivalência em que o participante não atingiu o critério e foi submetido ao retreino de todas as fases da etapa. Observa-se nessa tabela que os seis participantes tiveram que repetir um maior número de vezes os blocos da Etapa 2 do que os da Etapa 1. Na Etapa 1, apenas o PE2 e o PE4 tiveram que repetir o Teste de Equivalência $\mathrm{BC} /$ $\mathrm{CB}$, enquanto na Etapa 2, todos os participantes repetiram esse teste. Além disso, na Etapa 2, o PE2 e o PE3 tiveram que repetir o Teste de Equivalência $\mathrm{BD} / \mathrm{DB} / \mathrm{CD} / \mathrm{DC}$, e o PE3 e o PE4 o Teste Misto. As porcentagens de respostas de acordo com as contingências estabelecidas em TI e TT apresentadas pelos participantes do Grupo Extinção nos Testes Mistos das Etapas 1 e 2 variaram de $92,7 \%$ a $100 \%$. 
Tabela 2

Número de Repetições dos Blocos de Treinos e de Testes do Grupo Extinção nas Etapas 1 e 2 do Procedimento

\begin{tabular}{|c|c|c|c|c|c|c|c|}
\hline \multirow{2}{*}{ Etapas } & \multirow{2}{*}{ Fases } & \multicolumn{6}{|c|}{ Participantes } \\
\hline & & PE1 & PE2 & PE3 & PE4 & PE5 & PE6 \\
\hline \multirow[t]{9}{*}{1} & Treino BA & 2 & $2+1$ & 2 & $4+1$ & 3 & 3 \\
\hline & LB e Simetria AB & 1 & $1+1$ & 1 & $1+1$ & 1 & 1 \\
\hline & Treino CA & 2 & $13+1$ & 2 & $2+1$ & 3 & 2 \\
\hline & LB e Simetria AC & 1 & $1+1$ & 1 & $1+1$ & 1 & 1 \\
\hline & Equivalência $\mathrm{BC} / \mathrm{CB}$ & 1 & $1^{*+1}$ & 1 & $1^{*+1}$ & 1 & 1 \\
\hline & Treino DA & 2 & 2 & 2 & 2 & 3 & 2 \\
\hline & LB e Simetria AD & 1 & 1 & 1 & 1 & 1 & 1 \\
\hline & Equivalência $\mathrm{BD} / \mathrm{DB} / \mathrm{CD} / \mathrm{DC}$ & 1 & 1 & 1 & 1 & 1 & 1 \\
\hline & Teste Misto & 1 & 1 & 1 & 1 & 1 & 1 \\
\hline \multirow[t]{9}{*}{2} & Treino BA & $2+2$ & $1+1$ & $4+1+1+1$ & $2+1+2+1$ & $6+1$ & $2+1$ \\
\hline & LB e Simetria AB & $1+1$ & $1+1$ & $1+1+1+1$ & $1+1+1+1$ & $1+1$ & $1+1$ \\
\hline & Treino CA & $2+1$ & $2+1$ & $2+1+1+1$ & $2+1+1+1$ & $2+1$ & $3+1$ \\
\hline & LB e Simetria AC & 1 & $1+1$ & $1+1+1+1$ & $1+1+1+1$ & $1+1$ & $1+1$ \\
\hline & Equivalência $\mathrm{BC} / \mathrm{CB}$ & $1^{*+1}$ & $1^{*+1}$ & $1^{*+1} 1^{* *+1+1}$ & $1^{*+1} 1^{*+1 *+1}$ & $1 *+1$ & $1^{*+1}$ \\
\hline & Treino DA & 2 & $3+2$ & $2+1+1$ & $2+2$ & 2 & 2 \\
\hline & LB e Simetria AD & 1 & $1+1$ & $1+1+1$ & $1+1$ & 1 & 1 \\
\hline & Equivalência $\mathrm{BD} / \mathrm{DB} / \mathrm{CD} / \mathrm{DC}$ & 1 & $1^{*+1}$ & $1^{*+1+1}$ & $1+1$ & 1 & 1 \\
\hline & Teste Misto & 1 & 1 & $1^{*+1}$ & $1^{*+1}$ & 1 & 1 \\
\hline
\end{tabular}

Nota. O número 1 com asterisco indica os testes em que o participante não atingiu o critério de $90 \%$ de acertos, retornando a blocos anteriores antes de realizá-lo novamente.

Na Figura 1 estão as porcentagens de respostas de escolha dos estímulos de comparação nos blocos dos Testes Mistos das Etapas 1 e 2 (os dois primeiros pontos da abcissa) e sucessivos blocos de extinção da Etapa 3. Essas respostas foram classificadas de acordo como as seguintes categorias/rótulos: "TI", quando eram condizentes com o TI; "TT", quando eram condizentes com esse TT; "NA", quando correspondiam à escolha da chave com a frase "nenhuma das alternativas"; e "OR", quando o participante apresentava outras respostas, escolhendo estímulos que não correspondiam a nenhum dos tipos anteriores. Verifica-se na Figura 1 que, todos os participantes responderam com porcentagens acima de 90\% de acordo com o treino das Etapas 1 e 2, e nos blocos de extinção, com exceção do PE6, o desempenho dos participantes foi bastante semelhante. Todos esses cinco participantes apresentaram acima de $95 \%$ de respostas TT e abaixo de $5 \%$ de respostas TI e OR nos blocos de extinção. Devido ao achatamento dos dados dos participantes PE 1 à PE5 na Figura 1, os quais apresentaram predominantemente TT. As repostas TI apresentadas ao longo dos sucessivos blocos de extinção, que poderiam indicar ressurgência estão especificadas a seguir. O PE1 apresentou $4,2 \%$ e $2,1 \%$ nos Blocos 1 e 17 , respectivamente; o PE2 apresentou 2,1\% no Bloco 24; PE apresentou 2,1\% nos Blocos 23, 25, 27 e 28; o PE4 apresentou 2,1\% nos Blocos 3, 7, 12, 13, 15, 22, 23, 24, 27 e 28; o PE5 apresentou 4,2\% no Bloco 1 e 2,1\% nos Blocos 14, 17, 19, 21, 22 e 25. Nenhum dos participantes escolheu a opção NA. 
-O- Treino Tardio

_* Treino Inicial

- A - Outras Respostas

$-\square$ - Nenhuma das Alternativas
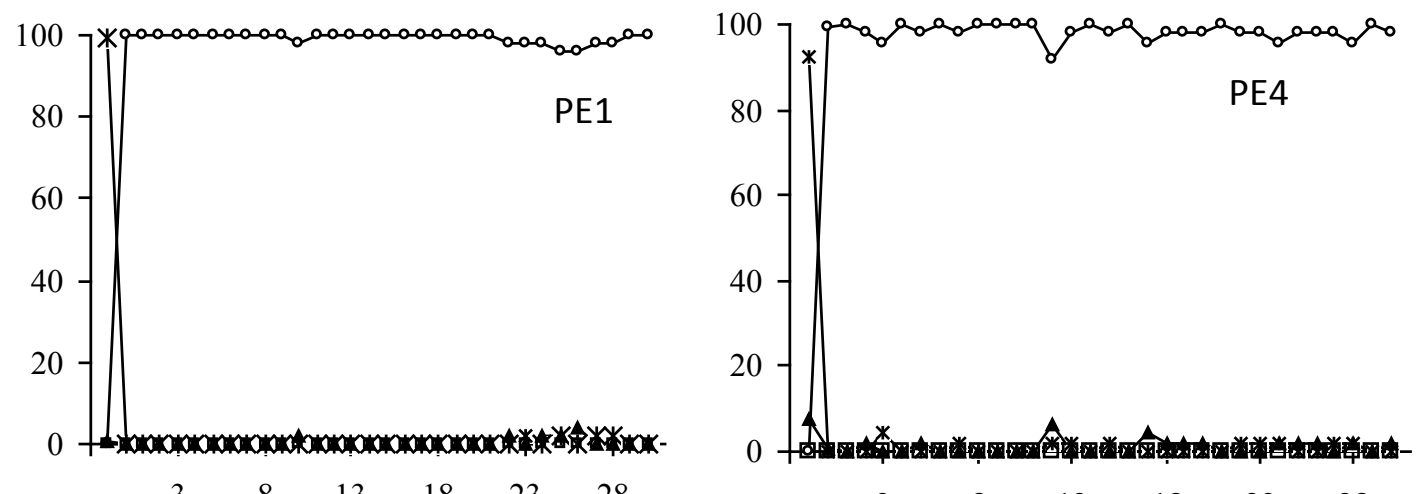

$\begin{array}{llllll}3 & 8 & 13 & 18 & 23 & 28\end{array}$
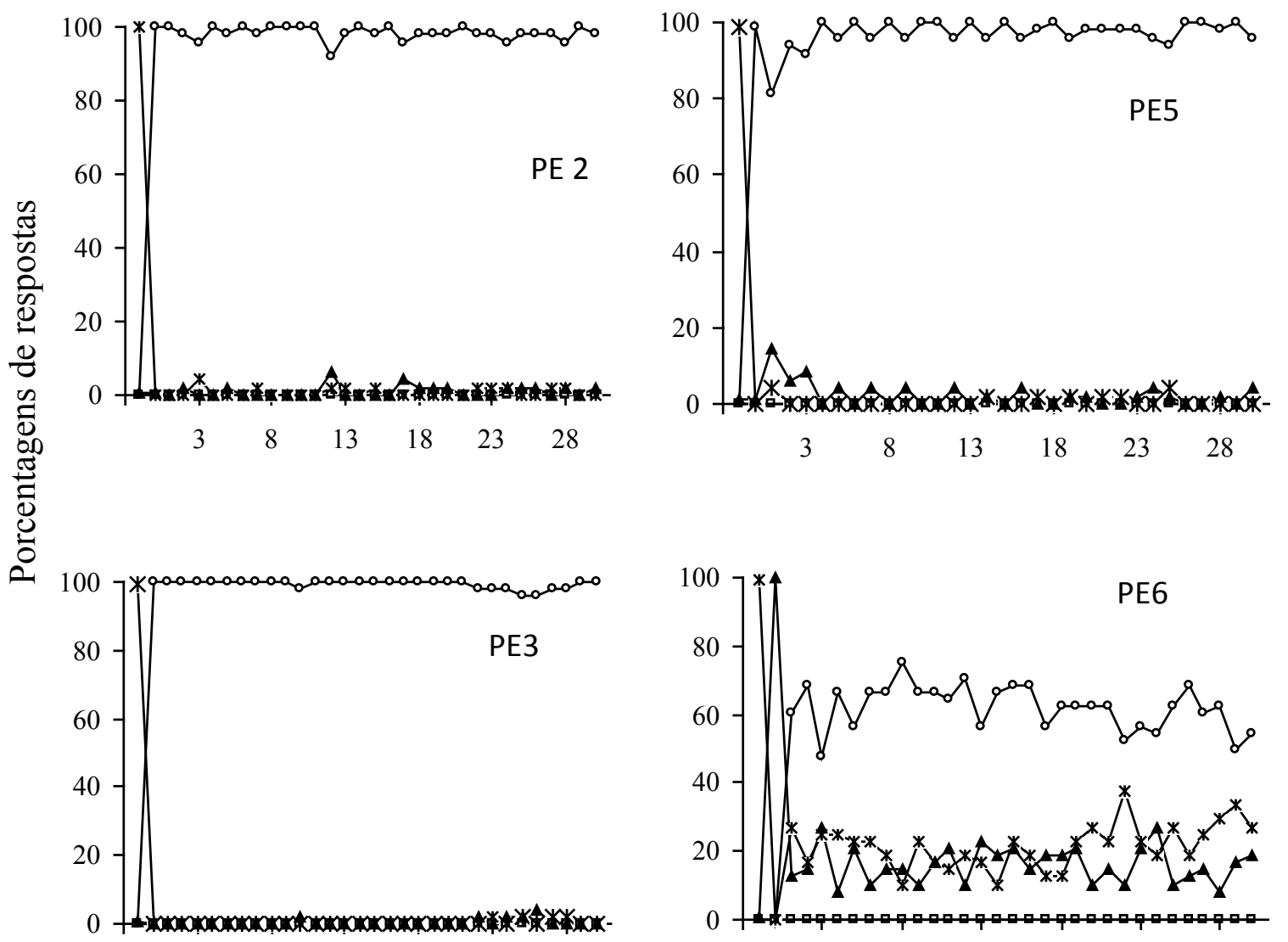

$\begin{array}{llllll}3 & 8 & 13 & 18 & 23 & 28\end{array}$

$\begin{array}{llllll}3 & 8 & 13 & 18 & 23 & 28\end{array}$

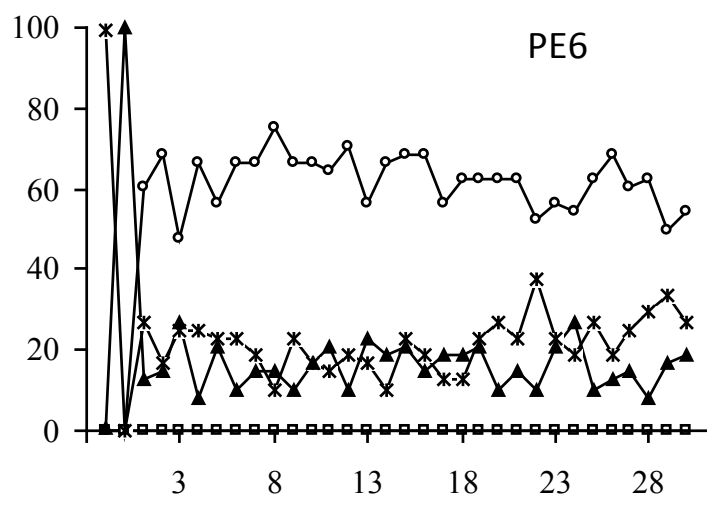

Testes Mistos das Etapas 1 e 2 e sucessivos Blocos de Extinção

Figura 1. Porcentagens de respostas apresentadas pelos participantes do Grupo Extinção nos Testes Mistos das Etapas 1 e 2 (Pontos 1 e 2 da abcissa) e sucessivos blocos de extinção da Etapa 3. 
Tabela 3

Número de Repetições dos Blocos de Treinos e Testes do Grupo Punição nas Etapas 1 e 2

\begin{tabular}{|c|c|c|c|c|c|c|c|}
\hline \multirow{2}{*}{ Etapas } & \multirow{2}{*}{ Fases } & \multicolumn{6}{|c|}{ Participantes } \\
\hline & & PP1 & PP2 & PP3 & PP4 & PP5 & PP6 \\
\hline \multirow[t]{9}{*}{1} & Treino BA & 3 & $6+1$ & 1 & 3 & 2 & 2 \\
\hline & LB e Simetria AB & 1 & $1+1$ & 1 & 1 & 1 & 1 \\
\hline & Treino CA & 2 & $4+1$ & 5 & 2 & 3 & 3 \\
\hline & LB e Simetria AC & 1 & $1+1$ & 1 & 1 & 1 & 1 \\
\hline & Equivalência BC/CB & 1 & $1^{*}+1$ & 1 & 1 & 1 & 1 \\
\hline & Treino DA & 2 & 3 & 2 & 3 & 2 & 2 \\
\hline & LB e Simetria AD & 1 & 1 & 1 & 1 & 1 & 1 \\
\hline & Equivalência BD/DB/CD/DC & 1 & 1 & 1 & 1 & 1 & 1 \\
\hline & Teste Misto & 1 & 1 & 1 & 1 & 1 & 1 \\
\hline \multirow[t]{9}{*}{2} & Treino BA & 3 & $3+1$ & $2+2$ & 3 & 3 & $3+2$ \\
\hline & LB e Simetria AB & 1 & $1+1$ & $1+1$ & 1 & 1 & $1+1$ \\
\hline & Treino CA & 3 & $3+1$ & $2+3$ & 2 & $4+2$ & 2 \\
\hline & LB e Simetria AC & 1 & $1+1$ & $1+1$ & 1 & $1+1$ & 1 \\
\hline & Equivalência BC/CB & 1 & $1^{*}+1$ & $1^{*}+1$ & 1 & 1 & 1 \\
\hline & Treino DA & 2 & 3 & 1 & $4+2$ & 2 & 2 \\
\hline & LB e Simetria AD & 1 & 1 & 1 & $1+1$ & 1 & 1 \\
\hline & Equivalência BD/DB/CD/DC & 1 & 1 & 1 & $1^{*}+1$ & 1 & 1 \\
\hline & Teste Misto & 1 & 1 & 1 & 1 & 1 & 1 \\
\hline
\end{tabular}

Nota. O número 1 com asterisco indica o teste de equivalência em que o participante não atingiu o critério de $90 \%$ de acertos, retornando a blocos anteriores antes de realizá-lo novamente.

Na Tabela 3 são apresentados os números de repetições dos blocos de treino e de teste do Grupo Punição nas Etapas 1 e 2 do procedimento. Observa-se nessa tabela que na Etapa 1, apenas o PP2 não atingiu o critério de $90 \%$ de acertos no Teste de Equivalência BC/CB, tendo sido submetido ao procedimento desde o princípio (Treino BA) e após a repetição do treino realizou o Teste de Equivalência $\mathrm{BC} / \mathrm{CB}$ novamente, tendo então atingido o critério. Dentre os demais participantes, PP3 realizou até cinco vezes o Treino $\mathrm{CA}$, mas esse e os demais participantes, ao serem submetidos ao Teste de Equivalência $\mathrm{BC} /$
$\mathrm{CB}$, atingiram o critério e não foram submetidos novamente às fases anteriores. Na Etapa 2, apenas o PP1 não teve que ser submetido novamente a blocos de teste. Dois participantes (PP2, PP3) não atingiram o critério no Teste de Equivalência $\mathrm{BC} / \mathrm{CB}$ e um deles (PP4) no Teste de Equivalência $\mathrm{BD} / \mathrm{DB} / \mathrm{CD} / \mathrm{DC}$. Outros dois (PP5 e PP6) não atingiram o critério de acertos em Testes de $\mathrm{LB} / \mathrm{Sim}$. As porcentagens de respostas de acordo com as contingências estabelecidas em TI e TT apresentadas pelos participantes do Grupo Punição nos Testes Mistos das Etapas 1 e 2 variaram de $90,6 \%$ a $100 \%$. 


\author{
-*. Treino Inicial \\ -O- Treino Tardio \\ - Outras Respostas \\ $-\square$ - Nenhuma das Alternativas
}
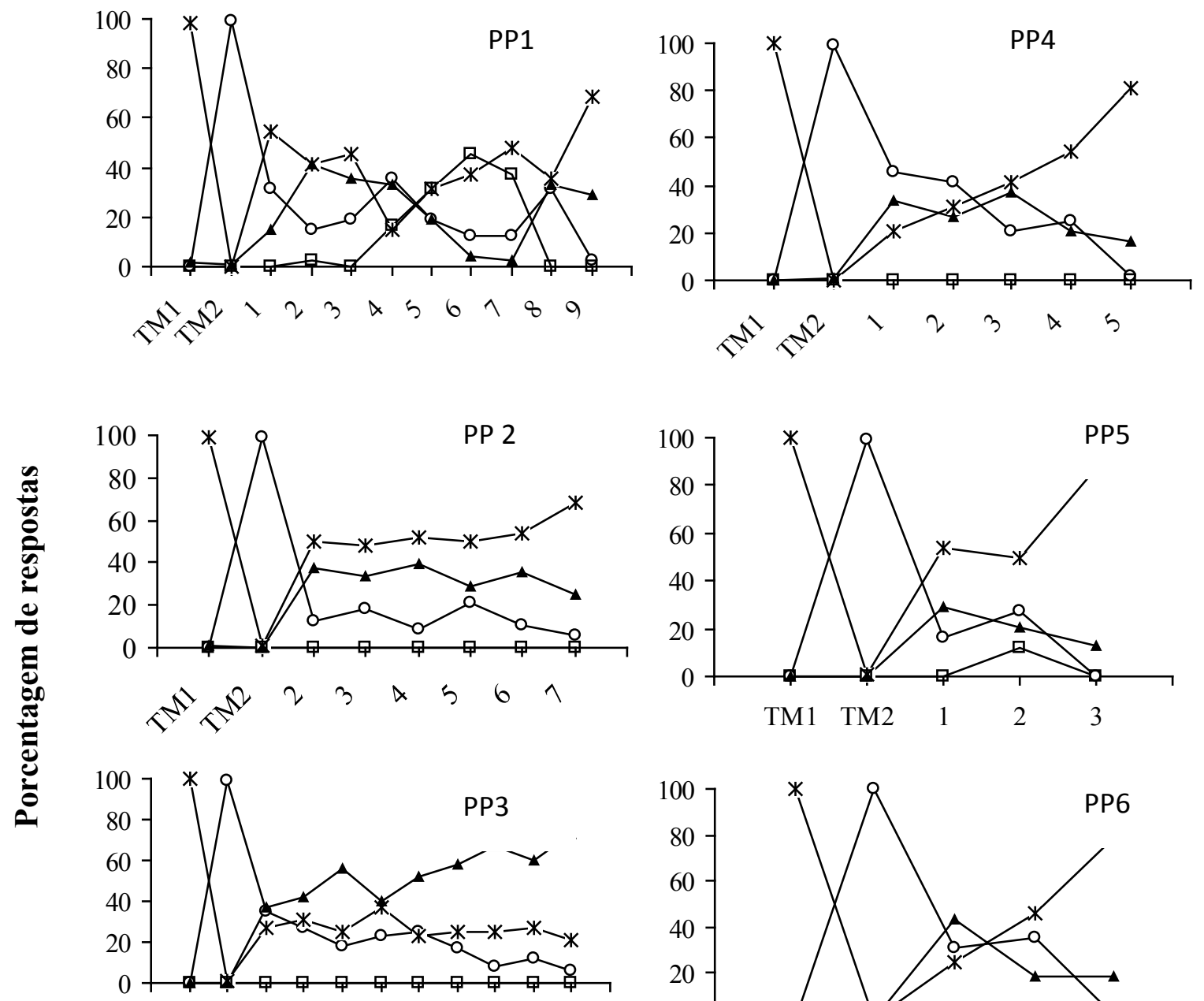

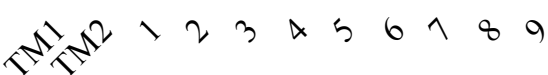

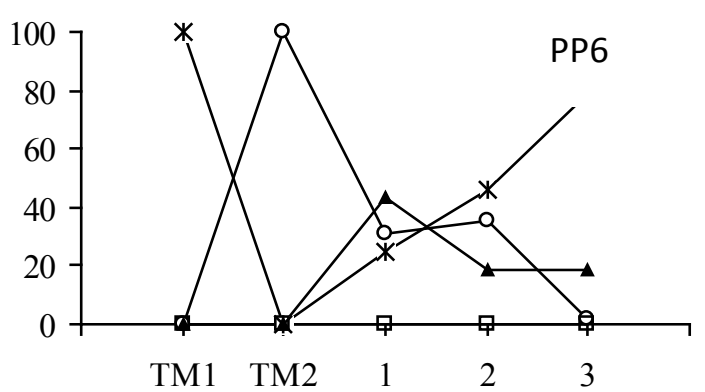

Testes Mistos das Etapas 1 e 2 e sucessivos Blocos de Punição

Figura 2. Porcentagens de respostas apresentadas pelos participantes do Grupo Punição nos Testes Mistos das Etapas 1 e 2 (TM1 e TM2) e sucessivos blocos de punição da Etapa 3. O número de blocos de punição variou de participante para participante devido ao critério de reexposição adotado.

Na Figura 2 estão representados os desempenhos dos participantes do Grupo Punição nos blocos dos Testes Mistos das Etapas 1 e 2, e nos blocos de punição da Etapa 3. Verifica-se que todos os participantes responderam com porcentagens acima de $90 \%$ de acordo com o treino das Etapas 1 e 2, e nos blocos de punição dos seis participantes, cinco (PP1, PP2, PP4, PP5 e
PP6) apresentaram aumento nas porcentagens de respostas TI ao longo dos sucessivos blocos. O PP4 apresentou maior tendência ao aumento, iniciando com $20 \%$ no primeiro bloco e terminando com $81 \%$ no último bloco. Esse aumento na porcentagem de respostas TI só ocorreu de forma progressiva ao longo dos blocos no caso de PP4 e de PP6. Verifica-se, ainda, na Figura 2, 
que todos os participantes apresentaram decréscimo na porcentagem de respostas TT, o qual não ocorreu de forma gradual e sucessiva ao longo dos blocos, pois em alguns blocos houve um decréscimo na porcentagem de TT e uma recuperação subsequente. No último bloco, todos os participantes apresentaram porcentagens de TT inferiores a $6 \%$. As porcentagens de OR tenderam, também, a diminuir ao longo dos blocos de punição, sendo que apenas o PP3 apresentou aumento dessas respostas. Apenas dois participantes (PP1 e PP5) apresentaram NA. No caso do PP1, essa resposta foi emitida em cinco dos nove blocos de punição, aos quais o participante foi submetido. No caso do PP5, NA foi emitida em um dos três blocos que o participante repetiu. Os participantes que apresentaram aumentos mais acentuados nas porcentagens de TI de um bloco para o outro foram PP5 e PP6.

Uma comparação entre os dados das Figuras 1 e 2 permite constatar que a diferença mais evidente é que a maioria dos participantes dos Grupos Extinção manteve porcentagens de TT acima de $90 \%$ ao longo de 30 blocos sucessivos de extinção, enquanto os participantes do Grupo Punição apresentaram redução na porcentagem de respostas, chegando a valores próximos a $2 \%$. Essa redução ocorreu em no máximo nove repetições dos blocos de punição em dois casos (PP1 e PP3), enquanto outros dois participantes (PP4 e PP5) atingiram esse valor em três sessões.

A Tabela 4 exibe o número de respostas TI, TT e OR dos participantes do Grupo Extinção e do Grupo Punição, por tipo de relação mantida no último bloco da Etapa 3. Como nenhum participante apresentou NA nesse bloco, os dados referentes a essa reposta não foram incluídos nessa tabela. Cada bloco era formado por 12 relações condicionais de LB, 12 de simetria e 24 de equivalência. Observa-se na Tabela 4 que cinco dos seis participantes do Grupo Extinção apresentaram um número de respostas máximas de TT e não emitiram TI, com exceção de PP4 que emitiu uma reposta TI. O PE6 apresentou resultados divergentes dos demais, com seis a sete repostas TT, quatro respostas TI e uma a seis repostas OR.

A maioria dos participantes do Grupo $\mathrm{Pu}$ nição apresentou predominantemente TI ( 8 a 12

Tabela 4

Número de Respostas dos Participantes no Último Bloco da Etapa 3, dos Grupos Extinção e Punição

\begin{tabular}{llccccccccc}
\hline & \multicolumn{8}{c}{ Tipo de Relação } \\
\cline { 3 - 10 } Grupos & Participantes & \multicolumn{1}{c}{ Linha de Base } & \multicolumn{3}{c}{ Simetria } & \multicolumn{3}{c}{ Equivalência } \\
\cline { 3 - 10 } & & TI & TT & OR & TI & TT & OR & TI & TT & OR \\
\hline Extinção & PE1 & 0 & 12 & 0 & 0 & 12 & 0 & 0 & 24 & 0 \\
& PE2 & 0 & 12 & 0 & 0 & 12 & 0 & 0 & 24 & 0 \\
& PE3 & 0 & 12 & 0 & 0 & 12 & 0 & 0 & 24 & 0 \\
& PE4 & 0 & 12 & 0 & 1 & 11 & 1 & 0 & 24 & 0 \\
& PE5 & 0 & 12 & 0 & 0 & 12 & 0 & 0 & 24 & 0 \\
& PE6 & 4 & 6 & 2 & 4 & 7 & 1 & 4 & 14 & 6 \\
& PP1 & 12 & 0 & 0 & 12 & 0 & 0 & 10 & 1 & 13 \\
& PP2 & 10 & 1 & 1 & 8 & 1 & 3 & 15 & 1 & 8 \\
& PP3 & 2 & 0 & 10 & 1 & 3 & 8 & 8 & 0 & 16 \\
& PP4 & 8 & 0 & 4 & 8 & 0 & 4 & 23 & 1 & 0 \\
& PP5 & 10 & 0 & 2 & 10 & 0 & 2 & 22 & 0 & 2 \\
& PP6 & 9 & 1 & 2 & 9 & 0 & 3 & 20 & 0 & 4 \\
\hline
\end{tabular}

Nota . $\mathrm{TI}=$ Treino Inicial; $\mathrm{TT}=$ Treino Tardio; $\mathrm{OR}=$ Outras Respostas. 
respostas de $\mathrm{LB}$ e de simetria, e 10 a 23 repostas de equivalência), com exceção de PP3, cujas respostas, em sua maioria, eram do tipo OR (10 de LB, 8 de simetria e 16 de equivalência). Destacase que PP3 apresentou apenas três respostas TT, que eram de simetria. Ao se comparar os dados do Grupo Extinção com os do Grupo Punição, na Tabela 4, verifica-se que apenas dois participantes do Grupo Extinção emitiram OR (PE5 e PE6), tendo havido maior variabilidade no caso do Grupo Punição.

\section{Discussão}

Os objetivos do presente estudo consistiram em investigar: (a) o efeito da opção de escolher "nenhuma das alternativas", sobre a emergência de relações de equivalência; e (b) o efeito dessa opção sobre a ressurgência de classes de equivalência inicialmente treinadas, após extinção ou a punição das respostas treinadas tardiamente. Verificou-se que todos os participantes exibiram emergência das relações equivalentes na Etapa 1 (A1-B1-C1-D1, A2-B2-C2-D2, A3-B3-C3-D3, $\mathrm{A} 4-\mathrm{B} 4-\mathrm{C} 4-\mathrm{D} 4)$ e quando as contingências foram alteradas, na Etapa 2, revertendo-se as relações condicionais, os participantes responderam de acordo com as novas contingências constatando-se a reorganização das classes de equivalência A1-B2-C3-D4, A2-B3-C4-D1，A3-B4-C1-D2, A4-B1-C2-D3. Além disso, observou-se que a maioria dos participantes não emitiu a resposta de escolher "nenhuma das alternativas", o que permite afirmar que essa condição não afetou a formação das classes de equivalência e não impediu a reorganização das classes.

Os resultados do presente estudo diferem dos obtidos por Duarte et al. (1998) e por Smeets et al. (2000), já que nas pesquisas desses autores, uma porcentagem inferior de participantes formou classes de equivalência, quando esses tiveram a oportunidade de deixar de escolher um dos estímulos de comparação, assinalando a alternativa "can't answer", do que quando essa opção não estava presente. Um aspecto que pode ter contribuído para essa diferença foi que no início do presente estudo, os participantes foram instruídos de que as relações entre os estímulos eram arbitrárias e que eles descobririam quais estímulos deveriam ser relacionados a partir das consequências de suas escolhas. Além disso, para que os participantes não considerassem a opção "nenhuma das alternativas" sem função a partir das contingências estabelecidas durante os treinos, ela só foi apresentada nos testes de relações emergentes de equivalência e, nessas fases, não era liberado feedback para essa opção de resposta. Assim, se no início do experimento os participantes foram informados de que só aprenderiam a responder corretamente observando as consequências de suas respostas e se escolher "nenhuma das alternativas" não forneceria esse tipo de feedback, então não era produtivo escolher essa alternativa. Essa pode, portanto, ter sido uma das variáveis que levou à diferença nos resultados dos estudos, ou seja, os participantes não ficaram sob controle desse estímulo.

A diferença nos resultados deste estudo e o de Duarte et al. (1998) pode, também, estar relacionada com o tipo de instrução dada aos participantes, conforme apontado no parágrafo anterior. Duarte et al., além dos efeitos da opção de resposta "can't answer", investigaram o efeito de uma instrução restritiva sobre a formação das classes de equivalência. Dois grupos de participantes foram submetidos ao procedimento de treino das relações condicionais por meio de protocolos impressos, nos quais eram apresentadas regras que explicitavam quais estímulos deviam ser relacionados. Um exemplo desse tipo de regra era: "quando o modelo for Д, escolha Ж”. O experimento envolvia três condições: na primeira condição não era fornecida nenhuma instrução adicional, além das regras de quais eram as relações condicionais corretas, como no exemplo anterior. Na segunda condição, era apresentada uma instrução restritiva, alertando o participante para responder apenas de acordo com as regras fornecidas: "Sua tarefa é usar APENAS essas instruções" (p. 636). Na terceira condição uma instrução não restritiva era fornecida: "Sua tarefa é usar essas instruções" (p. 636). Os autores observaram que a emergência das relações foi significativamente reduzida na condição em que a instrução restritiva era fornecida no caso do grupo que tinha a opção " $c a n$ 't answer". Esse resultado levou os autores a concluírem que instruções fornecidas aos partici- 
pantes afetam a probabilidade de formação das classes de equivalência e que os participantes assinalaram "can't answer" para escapar de ter que responder quando a instrução é restritiva "como se a equivalência de tais relações pudesse ser apenas um palpite e não uma certeza" (p. 642). Essa possibilidade (de os participantes não estarem certos de suas respostas) é uma condição que provavelmente não ocorreu em relação aos participantes do presente estudo devido ao tipo de protocolo usado, em que os blocos eram repetidos tantas vezes quantas fossem necessárias para que o critério de $90 \%$ de acertos fosse atingido (um critério de precisão exigente). Assim, respostas de esquiva por não ter certeza de qual resposta emitir não seriam esperadas. No geral, pode-se afirmar que com uma história experimental de escolha necessária de um dos estímulos de comparação, a introdução da opção "nenhuma das alternativas" não alterou a forma com que os participantes se comportavam diante das contingências do procedimento de MTS.

Em relação à ressurgência, os resultados permitem constatar que não houve alteração nas respostas de escolha quando o procedimento de extinção das classes tardiamente treinadas foi executado. Os participantes continuaram respondendo de acordo com as contingências treinadas tardiamente com porcentagens de acerto semelhantes àquelas apresentadas no Teste Misto da Etapa 2 (acima de 90\%), portanto, não houve extinção, enquanto processo, das respostas de acordo com TT. Por outro lado, para o Grupo Punição, o feedback negativo dado para as respostas que estavam de acordo com o TT alterou as respostas de escolha dos participantes, os quais deixaram de responder de acordo com esse treino para uma porcentagem inferior a $10 \% \mathrm{em}$ menos de 10 blocos. Esses resultados corroboram àqueles obtidos por Castro e Haydu (2009), Haydu et al. (2007), Wilson e Hayes (1996), e de uma parte dos participantes de Hernández et al. (2008). Assim, pode-se concluir que a disponibilidade de uma opção "nenhuma das alternativas" durante os testes de equivalência e durante a condição de ressurgência não afetou o desempenho dos participantes, não confirmando a hipótese de Wilson e Hayes, e de Castro e Haydu de que condições experimentais menos restritas, em que o participante não tivesse que necessariamente escolher um dos estímulos de comparação, poderiam contribuir para que se observe a ressurgência de classes de equivalência induzida por extinção. O presente estudo permite ainda concluir que a opção "nenhuma das alternativas" apresentada nos teste de equivalência não impediu que emergissem relações condicionais entre estímulos e que essas relações fossem posteriormente reorganizadas formando novas classes, quando as contingências foram alteradas.

Uma vez que não houve diminuição de TT na condição de extinção, não foi possível investigar o efeito da opção de escolher "nenhuma das alternativas", sobre a ressurgência de relações de equivalência nessa condição. Assim uma variável adicional a ser considerada em estudos futuros de indução da ressurgência de classes de equivalência é o tipo de consequência liberada para as respostas de escolha dos participantes, para que, conforme sugeriram Castro e Haydu (2009), se amplie o que pode produzir extinção de classes de equivalência. Por exemplo, se as consequências fossem estímulos trocados por dinheiro, como foi feito em um estudo recente (Doughty \& Oken, 2008) em que a ressurgência foi demonstrada em três de quatro participantes, haveria a possibilidade de se ter uma contingência de extinção mais apropriada do que a mera repetição dos blocos de teste. Uma análise de questões sobre o tipo de consequência é apresentada nos experimentos desenvolvidos com seres humanos (Costa et al., 2008; Salgado, Cançado, $\&$ Costa, 2011), que demonstraram que o tipo do reforçador é uma variável que afeta o comportamento de seres humanos submetidos a esquemas de reforço e sugeriram que essa pode ser uma variável que contribui para as diferenças obtidas nos experimentos de esquemas de reforço com seres humanos e não humanos.

\section{Referências}

Bortoloti, R., de Rose, J. C., \& Galvão, O. de F. (2005). Tempo de detecção de estímulos abstratos equivalentes a expressões faciais. Temas em Psicologia, 13, 52-60.

Castro, T. C., \& Haydu, V. B. (2009). Efeitos da punição e da extinção na ressurgência de relações 
equivalentes. Acta Comportamentalia, 17, 211 223.

Costa, C. E., Banaco, R. A., Longarezi, D. M., Martins, E. V., Maciel, E. M., \& Sudo, C. H. (2008). Tipo de reforçador como variável moduladora dos efeitos da história em humanos. Psicologia: Teoria e Pesquisa, 24, 251-262.

de Rose, J. C., Kato, O. M., Thé, A. P. G., \& Kledaras, J. B. (1997). Variáveis que afetam a formação de classes de estímulos: Estudos sobre efeitos do arranjo de treino. Acta Comportamentalia, 5, 143-163.

Doughty, A. H., \& Oken, G. (2008). Extinction-induced response resurgence: A selective review. The Behavior Analyst Today, 9, 27-33. Retrieved from http://www.baojournal.com/VOL9/BAT\%209-1.pdf

Duarte, A. M., Eikeseth, S., Rosales Ruiz, J., \& Baer, D. M. (1998). The effects of a can't answer response option and instructions on stimulus equivalence. The Psychological Record, 48, 631-646.

Eikeseth, S., Rosales-Ruiz, J., Duarte, A., \& Baer, D. M. (1997). The quick development of equivalence classes in a paper-and-pencil format through written instructions. The Psychological Record, 47, 275-284.

Epstein, R. (1983). Resurgence of previously reinforced behavior during extinction. Behavior Analysis Letters, 3, 391-397.

Green, G., \& Saunders, R. R. (1998). Stimulus equivalence. In P. Latal (Ed.), Handbook of Research Methods in Human Operant Behavior (pp. 229. 261). New York: Plenum.

Haydu, V. B., Batista, A. P., \& Serpeloni, F. (2007). Reorganização e ressurgência de relações equivalentes instruídas e modeladas por contingências: Efeito da extinção. Temas em Psicologia, 15, 181-206.

Hernández, A., Medina, I. F., \& Erazo, L. E. (2008). Resurgencia de conductas simbólicas: una aproximación experimental. Acta Colombiana de Psicología, 11, 141-151. Recuperado de http://redalyc.uaemex.mx/redalyc/src/inicio/ArtPdfRed.jsp?iCve $=59331202$

Lattal, K. A., \& St. Peter Pipkin, C. (2009). Resurgence of previously reinforced responding: Research and application. The Behavior Analyst Today, 10, 254-265. Retrieved from http://www. baojournal.com/VOL-10/BAT\%2010-2
Magalhães, P. G. S., \& Assis, G. J. A. (2011). Equivalência monetária em crianças surdas. Temas em Psicologia, 19, 443-458.

Reed, P., \& Morgan, T. A. (2006). Resurgence of response sequences during extinction in rats shows a primacy effect. Journal of the Experimental Analysis of Behavior, 86, 307-315.

Salgado, R. C., Cançado, C. R. X., \& Costa, C. E. (2011). Efeitos do reforçador empregado em história de reforço recente e remota. Psicologia: Teoria e Pesquisa, 27, 119-130.

Sidman, M. (1994). Equivalence Relations: A research story. Boston, MA: Authors Cooperative.

Sidman, M., \& Cresson, O. (1973). Reading and crossmodal transfer of stimulus equivalences in severe retardation. American Journal of Mental Deficiency, 77, 515-523.

Smeets, P. M., Dymond, S., \& Barnes-Holmes, D. (2000). Instructions, stimulus equivalence, and stimulus sorting: Effects of sequential testing arrangements and a default option. The Psychological Record, 50, 339-354.

Souza, S. R. de, Goyos, C., Silvares, E. F. M., \& Saunders, R. (2007). Emergence of printing and spelling skills from constructed-response matching-to-sample instruction (CRMTS). European Journal of Behavior Analysis, 8, 49-64.

Spencer, T. J., \& Chase, P. N. (1996). Speed analysis of stimulus equivalence. Journal of the Experimental Analysis Behavior, 65, 643-659.

Villas-Bôas, A. V., Murayama, V. K., \& Tomanari, G. Y. (2005). Ressurgência: conceitos e métodos que podem (ou não) contribuir para a Análise do Comportamento. In H. Guilhardi \& N. C. de Aguirre (Orgs.), Sobre Comportamento e Cognição: Expondo a variabilidade (Vol. 15, pp. 18-28). Santo André, SP: ESEtec.

Wilson, K. G., \& Hayes, S. C. (1996). Resurgence of derived stimulus relations. Journal of the Experimental Analysis of Behavior, 66, 267-281. 